\title{
Postoperative Treatment of Resectable Pancreatic Cancer With Positive Peritoneal Lavage Cytology: A Multicentre Retrospective Study
}

\author{
AKIKO TODAKA ${ }^{1}$, SATOSHI NARA ${ }^{2}$, FUYUHIKO MOTOI $^{3,4}$, SOICHIRO MORINAGA $^{5}$, REISHI TOSHIYAMA ${ }^{6}$, \\ RYOTA HIGUCHI $^{7}$, MASARU KONISHI ${ }^{8}$, HIROFUMI SHIRAKAWA ${ }^{9}$, HIDETAKA TSUMURA ${ }^{10}$, \\ HIROYUKI OKUYAMA ${ }^{11}$, HIROAKI NAGANO ${ }^{12}$, KAZUHIKO SHIOJI ${ }^{13}$, \\ KEISHI SUGIMACHI ${ }^{14}$, AKINORI ASAGI ${ }^{15}$, NOBUMASA MIZUNO ${ }^{16}$ and JUNJI FURUSE ${ }^{17}$ \\ ${ }^{1}$ Division of Gastrointestinal Oncology, Shizuoka Cancer Center, Shizuoka, Japan; \\ ${ }^{2}$ Department of Hepatobiliary and Pancreatic Surgery, National Cancer Center Hospital, Tokyo, Japan; \\ ${ }^{3}$ Department of Surgery, Tohoku University Graduate School of Medicine, Miyagi, Japan; \\ ${ }^{4}$ Department of Surgery I, Yamagata University Graduate School of Medical Science, Yamagata, Japan; \\ ${ }^{5}$ Department of Gastrointestinal Surgery, Kanagawa Cancer Center, Kanagawa, Japan; \\ ${ }^{6}$ Department of Surgery, National Hospital Organization Osaka National Hospital, Osaka, Japan; \\ ${ }^{7}$ Department of Surgery, Institute of Gastroenterology, Tokyo Women's Medical University, Tokyo, Japan; \\ ${ }^{8}$ Department of Hepatobiliary and Pancreatic Surgery, National Cancer Center Hospital East, Chiba, Japan; \\ ${ }^{9}$ Department of Hepatobiliary-Pancreatic Surgery, Tochigi Cancer Center, Tochigi, Japan; \\ ${ }^{10}$ Department of Gastroenterological Oncology, Hyogo Cancer Center, Hyogo, Japan; \\ ${ }^{11}$ Department of Clinical Oncology, Kagawa University, Kagawa, Japan; \\ ${ }^{12}$ Department of Gastroenterological, Breast, and Endocrine Surgery, \\ Yamaguchi University Graduate School of Medicine, Yamaguchi, Japan; \\ ${ }^{13}$ Department of Internal Medicine, Niigata Cancer Center Hospital, Niigata, Japan; \\ ${ }^{14}$ Department of Hepatobiliary-Pancreatic Surgery, \\ National Hospital Organization Kyushu Cancer Center, Fukuoka, Japan; \\ ${ }^{15}$ Department of Gastrointestinal Medical Oncology, \\ National Hospital Organization Shikoku Cancer Center, Ehime, Japan; \\ ${ }^{16}$ Department of Gastroenterology, Aichi Cancer Center Hospital, Aichi, Japan; \\ ${ }^{17}$ Department of Medical Oncology, Kyorin University Faculty of Medicine, Tokyo, Japan
}

\begin{abstract}
Background/Aim: We aimed to evaluate pancreatic cancer (PC) with positive peritoneal lavage cytology (CYI) outcomes following a change in adjuvant therapy. Patients and Methods: The clinicopathological data of patients with pancreatic adenocarcinoma with CYI at 14 institutions, between 2007 and 2015, were collected and analyzed. Results:
\end{abstract}

This article is freely accessible online.

Correspondence to: Akiko Todaka, Division of Gastrointestinal Oncology, Shizuoka Cancer Center, 1007 Shimonagakubo, Nagaizumi-cho, Sunto-gun, Shizuoka 411-8777, Japan. Tel: +81 559895222, Fax: +81 559895551, e-mail: a.todaka@scchr.jp

Key Words: Adjuvant therapy, gemcitabine, pancreatic cancer, positive peritoneal lavage cytology, postoperative chemotherapy, S-1.
Of the 124 eligible patients, 114 underwent macroscopically curative resection. Of the 114 patients, 80 (70\%) did not have early recurrence and received postoperative chemotherapy that was $S-1$ in 43 (54\%), gemcitabine in 31 (39\%), and others in six (7\%). The median overall survival was 21.0 months in $S-1$ and 19.2 in gemcitabine therapy $(p=0.23)$, whereas the median relapse-free survival was 10.2 and 7.1 months $(p=0.03)$, respectively. Conclusion: Following the change in adjuvant therapy, most $P C$ patients with CY1 who underwent macroscopically curative resection received $S-1$; however, it was insufficient. Further development of postoperative chemotherapy is required.

Pancreatic cancer is the fourth leading cause of cancer-related deaths in the United States and Japan $(1,2)$. The incidence of pancreatic cancer is increasing in Japan, and the 5-year survival rate is $8.0-9.0 \%$ (2). The only management modality 


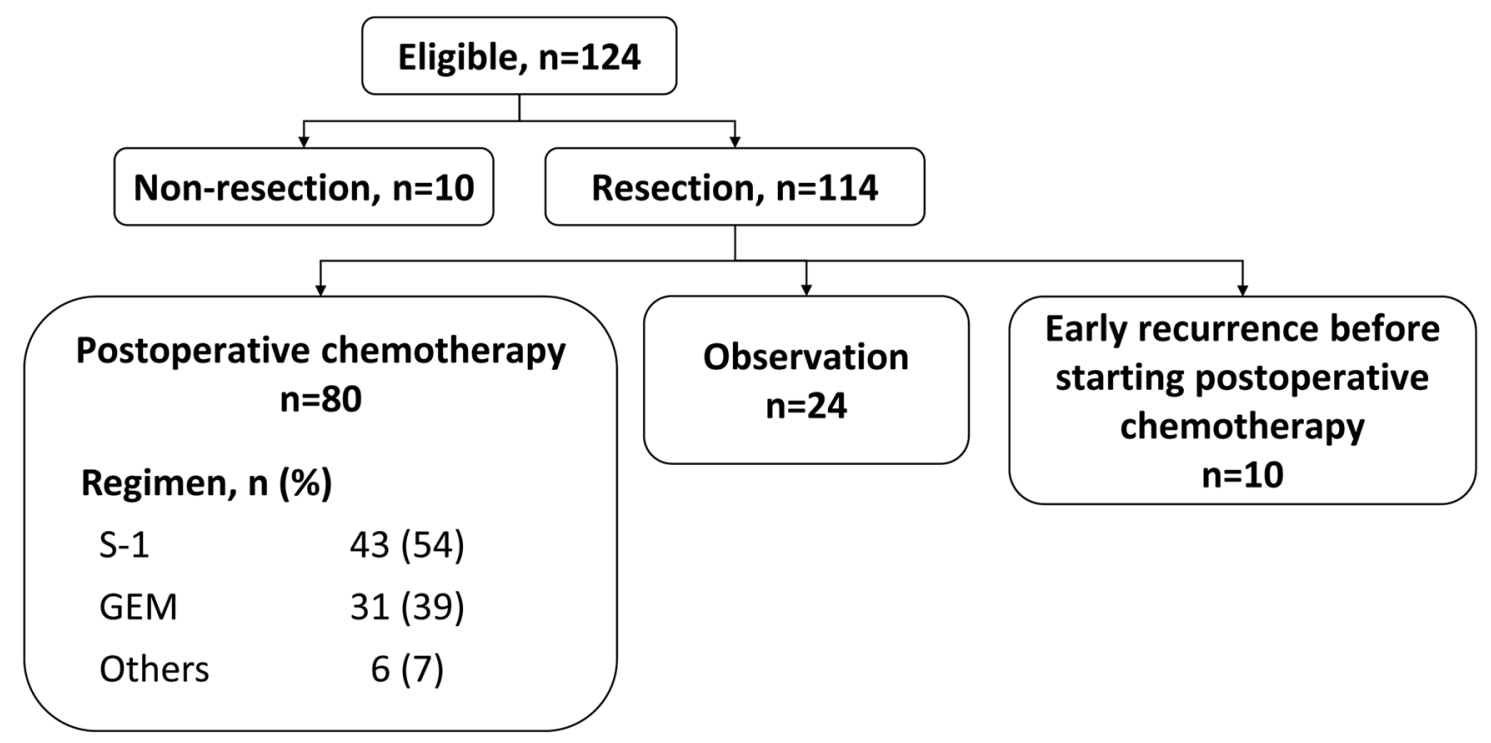

Figure 1. Patient treatment characteristics.

with curative potential for pancreatic cancer is surgery; however, more than half of patients cannot undergo resection due to locally advanced disease or metastatic lesions at the time of diagnosis.

Positive peritoneal lavage cytology (CY1) in patients with resectable pancreatic cancer is equivalent to M1 disease according to the National Comprehensive Cancer Network guidelines and the American Joint Committee on Cancer (AJCC) Staging Manual (3, 4). In Japan, macroscopically curative resection is often performed in patients with pancreatic cancer who do not have uncurable resection factors other than CY1; however, previous reports have shown poor prognosis $(5,6)$. In a retrospective study of 69 patients with pancreatic ductal adenocarcinoma with CY1 who underwent margin-negative resection in seven institutions in Japan, between 2001 and 2011, the overall survival (OS) of patients with CY1 was significantly worse than that of those with negative peritoneal lavage cytology (CY0) (16 vs. 25 months, respectively; $p<0.001$ ), and adjuvant chemotherapy showed no improvement in survival (5). In another retrospective study of the Pancreatic Cancer Registry in Japan, between 2008 and 2012, 106 patients with CY1 who underwent tumour resection were enrolled. In this study, the median OS was 17.5 months, and patients who received adjuvant chemotherapy had better survival than those who did not (18.2 vs. 12.6 months, respectively; $p<0.04$ ) (6). Although the survival of patients with CY1 was worse than that of those with CY0, resection followed by adjuvant chemotherapy resulted in better outcomes compared to chemotherapy alone.

In 2007, the Charité Onkologie (CONKO)-001 trial showed that adjuvant chemotherapy with gemcitabine improved survival compared to surgery alone (7). In 2013, the Japan Adjuvant Study Group of Pancreatic Cancer (JASPAC)-01 trial showed the superiority of S-1 over gemcitabine as adjuvant chemotherapy for resected pancreatic cancer (5-year OS: $44.1 \%$ vs. $24.4 \%$, respectively; $p<0.0001$ ) (8). Since then, adjuvant chemotherapy with S-1 has been the standard of care in Japan.

S-1 is also administered to patients with CY1 who have undergone macroscopically curative resection. Previous studies $(5,6)$ have included patients treated until 2012; therefore, the subsequent outcomes following the change in the standard adjuvant therapy are unknown. This study aimed to clarify the multidisciplinary treatment and outcome of patients with resectable pancreatic cancer with CY1, in Japanese clinical practice.

\section{Patients and Methods}

Study design and participants. This was a multicentre, retrospective, observational study. Patients with pancreatic adenocarcinoma with CY1 and no other non-curative resection factors for laparotomy or laparoscopy, at 14 institutions, between 2007 and 2015, were enrolled. Patients who received preoperative treatment, resection, or no resection were also eligible. Patients with histopathological types other than adenocarcinoma, such as mixed adenoneuroendocrine carcinoma, were excluded. Collection of peritoneal lavage fluid was performed according to the Japanese General Rules for the Study of Pancreatic Cancer (9). Immediately after laparotomy, $100 \mathrm{~mL}$ of physiological saline was injected into the abdominal cavity, and the washing solution was collected from the pouch of Douglas. Smears were prepared from the centrifuged deposit, and examined by experienced pathologists after conventional Papanicolaou and Giemsa staining. CY1 was defined as Class IV or V, according to the 
Papanicolaou classification. The common adjuvant chemotherapy regimens were gemcitabine alone $\left(1,000 \mathrm{mg} / \mathrm{m}^{2}\right.$, intravenously administered on days 1,8 , and 15 , every 4 weeks) or S-1 alone (80$120 \mathrm{mg} /$ day according to the body surface area for 28 days, followed by a 14-day rest period, every 6 weeks). Postoperative treatment was defined as treatment that commenced without recurrence within 3 months after resection, and treatment duration was determined by the investigators. Early recurrence was defined as recurrence before the initiation of postoperative chemotherapy. The study was approved by the ethics committee of each participating institution, and was conducted in accordance with the ethical guidelines for epidemiological research. The requirement for written informed consent was waived owing to the retrospective nature of the study. Investigators informed participants of their right to opt out of the study via public announcements. The study was registered in the University Hospital Medical Information Network Clinical Trials Registry (UMIN000032477).

Assessment. The following data were collected: clinical data, including age, sex, Eastern Cooperative Oncology Group performance status (ECOG PS), laboratory data, perioperative treatment, recurrence, and survival; surgical data, including type of surgery, concomitant vascular resection, and postoperative complications according to the Clavien-Dindo classification; and pathological data, including tumour differentiation, $\mathrm{T}$ and $\mathrm{N}$ status according to the AJCC TNM classification (eighth edition), tumour size, resection margin status, and number of dissected and metastatic lymph nodes $(4,10,11)$. The Glasgow Prognostic Score (GPS) was calculated as follows: patients with albumin levels $\geq 3.5 \mathrm{~g} / \mathrm{dl}$ and Creactive protein (CRP) levels $\leq 1.0 \mathrm{mg} / \mathrm{dl}$ were considered to have a GPS of 0 ; those with albumin levels $<3.5 \mathrm{~g} / \mathrm{dl}$ or CRP levels $>1.0$ $\mathrm{mg} / \mathrm{dl}$ were considered to have a GPS of 1 ; and those with both decreased albumin and increased CRP levels were considered to have a GPS of $2(12,13)$. The blood neutrophil-to-lymphocyte ratio (NLR) was calculated as the absolute neutrophil count divided by the absolute lymphocyte count. The outcomes of patients who received S-1 or gemcitabine therapy as postoperative treatment were examined.

Statistical analyses. The Kaplan-Meier method was used to estimate OS and relapse-free survival (RFS). OS was defined as the time from the date of laparotomy or laparoscopy with peritoneal lavage cytology to death from any cause. RFS was defined as the time from the date of resection to the diagnosis of recurrence or death from pancreatic cancer. The log-rank test was used to compare the survival curves. Categorical variables were compared using the $\chi^{2}$ test and continuous variables were compared using the Mann-Whitney U-test. The Cox proportional hazards regression model was used to perform univariate and multivariate survival analyses of patients who underwent macroscopically curative resection. The included variables were age, sex, ECOG PS, endoscopic ultrasound-guided fine needle aspiration, neoadjuvant therapy, NLR, GPS, carbohydrate antigen 19-9 (CA19-9) levels, type of surgery, concomitant vascular resection, pathological $\mathrm{T}$ and $\mathrm{N}$ stages, resection margin status, tumour differentiation, and postoperative chemotherapy. Statistically significant variables in the univariate analysis were included in the multivariate analysis. Statistical significance was set at $p<0.05$. Statistical analyses were performed using SPSS Version 26.0 for Windows (Chicago, IL, USA).
Table I. Patient characteristics.

\begin{tabular}{|c|c|c|}
\hline Characteristic & $\begin{array}{l}\text { Non-resection } \\
\text { group } \\
(\mathrm{n}=10)\end{array}$ & $\begin{array}{l}\text { Resection } \\
\text { group } \\
(\mathrm{n}=114)\end{array}$ \\
\hline \multicolumn{3}{|l|}{ Age (years) } \\
\hline Median (range) & $75(62-82)$ & $66(44-85)$ \\
\hline \multicolumn{3}{|l|}{ Gender } \\
\hline Male/Female & $6 / 4$ & $67 / 47$ \\
\hline \multicolumn{3}{|l|}{ ECOG PS } \\
\hline 0/1/Unknown & $3 / 7 / 0$ & $92 / 19 / 3$ \\
\hline \multicolumn{3}{|c|}{ Neoadjuvant therapy } \\
\hline Yes/No & $2 / 8$ & $15 / 99$ \\
\hline \multicolumn{3}{|l|}{ EUS-FNA } \\
\hline Yes/No & $2 / 8$ & $27 / 87$ \\
\hline \multicolumn{3}{|c|}{ CA19-9 level (U/ml) } \\
\hline Median (range) & $1,092(157-12,770)$ & $212.7(1-77,067)$ \\
\hline \multicolumn{3}{|l|}{ NLR } \\
\hline Median (range) & $2.49(1.24-6.23)$ & $2.31(0.39-8.21)$ \\
\hline \multicolumn{3}{|l|}{ GPS } \\
\hline 0/1/2/Unknown & $8 / 0 / 2 / 0$ & $87 / 16 / 5 / 6$ \\
\hline
\end{tabular}

ECOG PS: Eastern Cooperative Oncology Group performance status; EUS-FNA: endoscopic ultrasound-fine needle aspiration; CA19-9: carbohydrate antigen 19-9; NLR: neutrophil-to-lymphocyte ratio; GPS: Glasgow Prognostic Score.

\section{Results}

Patient characteristics. A total of 127 patients were registered from 14 institutions. Three patients (two with noadenocarcinoma and one with liver metastasis) were excluded. Thus, data from 124 patients were included in the final analysis. The median age was 67 years, and almost all patients had an ECOG PS of 0 or 1 . Of the 124 patients, 114 underwent macroscopically curative resection (Figure 1). The characteristics of the patients in the unresected and resected groups are shown in Table I. Patients who did not undergo resection were older than those who underwent resection. Of the 10 patients in the non-resected group, five had other reasons besides CY1 to avoid resection, such as old age or invasive surgery; the remaining five discontinued surgery because of CY1 alone. The surgical and pathological characteristics of the 114 patients undergoing macroscopically curative resection are shown in Table II. Of the 114 patients, distal pancreatectomy with celiac axis resection and total pancreatectomy were performed in seven $(6.1 \%)$ and eight $(7.0 \%)$ patients, respectively; thirty-four patients $(29.8 \%)$ underwent combined vascular resection. The median maximum tumour diameter was $35 \mathrm{~mm}$ (range $=10-100 \mathrm{~mm}$ ), and the median number of metastatic lymph nodes was 2 (range $=0-24$ ). According to the AJCC staging system (eighth edition), 44 patients $(38.6 \%)$ had pathological T3 stage, and $43(37.7 \%)$ and $45(39.5 \%)$ had pathological N1 and N2 stages, respectively. Of the patients 
Table II. Surgical and pathological characteristics.

\begin{tabular}{lc}
\hline Characteristic & Patients (n=114) \\
\hline Type of surgery & \\
PD/DP/DP-CAR/TP & $44 / 55 / 7 / 8$ \\
Concomitant vascular resection & \\
$\quad$ Yes/No & $34 / 80$ \\
Postoperative complications ( $\geq$ CD III) & $31 / 83$ \\
$\quad$ Yes/No & \\
Tumour differentiation & $27 / 74 / 13$ \\
$\quad$ Well/Mod/Poor & \\
T stage (AJCC $\left.8^{\text {th }}\right)$ & $8 / 62 / 44$ \\
1/2/3 & \\
N stage (AJCC $8^{\text {th }}$ ) & $26 / 43 / 45$ \\
0/1/2 & \\
Resection margin status & $76 / 31 / 7$ \\
R0/R1/Unknown & \\
Tumour size (mm) & $35(10-105)$ \\
Median (range) & \\
Number of dissected LNs & $30(1-100)$ \\
Median (range) & \\
Number of positive LNs & $2(0-24)$ \\
Median (range) &
\end{tabular}

AJCC 8th: American Joint Committee on Cancer staging system (eighth edition); CD: Clavien-Dindo classification; DP: distal pancreatectomy; DP-CAR: distal pancreatectomy with coeliac axis resection; LN: lymph node; PD: pancreatoduodenectomy; TP: total pancreatectomy.

who underwent macroscopically curative resection, 80 (70\%) had no recurrence and started postoperative chemotherapy within 3 months after resection (Figure 1). Almost all patients received the same regimen of adjuvant therapy, following curative resection. The postoperative chemotherapy regimen was S-1 in 43 patients $(54 \%)$, gemcitabine in $31(39 \%)$, and others in six $(7 \%)$. Ten patients $(9 \%)$ had early recurrence before starting postoperative chemotherapy, and $24(21 \%)$ were followed up without postoperative treatment.

Survival and recurrence. The median OS and RFS in the resected group were 16.7 and 7.2 months, respectively, and the median OS in the non-resected group was 9.2 months. Among patients who underwent macroscopically curative resection, the median OS of patients who received postoperative treatment without early recurrence was 20.6 months, and that of those undergoing observation with no postoperative treatment or with early recurrence were 13.8 and 7.9 months, respectively [hazard ratio (HR $=0.67,95 \%$ confidence interval $(\mathrm{CI})=0.41-1.1 ; p=0.11]$ (Figure 2).

Recurrence was observed in $106(93 \%)$ of the 114 patients who underwent macroscopically curative resection. The major sites of recurrence were the peritoneum (39\%), liver (34\%), local recurrence (22\%), lymph nodes $(13 \%)$, and lungs $(10 \%)$.
Univariate and multivariate analyses. In the univariate analysis, the type of surgery, concomitant vascular resection, $\mathrm{T}$ stage, $\mathrm{N}$ stage, and resection margin status were significant prognostic factors for OS, while the type of surgery, concomitant vascular resection, $\mathrm{T}$ stage, $\mathrm{N}$ stage, tumour differentiation, and postoperative chemotherapy were significant prognostic factors for RFS. In the multivariate analysis, total pancreatectomy and $\mathrm{R} 1$ resection were independent poor prognostic factors for OS, while T stage and tumour differentiation were significant prognostic factors for RFS (Table III and Table IV).

Comparison between $S-1$ and gemcitabine. The characteristics of patients who received postoperative chemotherapy with $\mathrm{S}$ 1 and gemcitabine are shown in Table V. There were no significant differences between both treatment groups in terms of background, surgical, and pathological factors. The median OS was 21.0 months in the $\mathrm{S}-1$ group and 19.2 in the gemcitabine group $(\mathrm{HR}=0.73,95 \% \mathrm{CI}=0.44-1.22 ; p=0.23)$; the median RFS was 10.2 and 7.1 months, respectively ( $\mathrm{HR}=0.58$, 95\% CI $=0.36-0.95 ; p=0.03$ ) (Figure 3 ). The site of recurrence was similar in both treatments (Table VI).

\section{Discussion}

This is the first study to clarify the outcome of postoperative treatment, according to the regimen, for patients with CY1 who underwent macroscopically curative resection. Most patients received adjuvant chemotherapy after curative resection for pancreatic cancer. The median OS and RFS with S-1 and gemcitabine as adjuvant treatment were 21.0 and 19.2 months and 10.2 and 7.1 months, respectively. Compared to gemcitabine, S-1 improved RFS; however, OS was comparable.

Several studies have shown that postoperative treatment did not significantly improve OS in patients with CY1 $(5,14)$. Previous studies reported that the median OS of patients with CY1 who underwent macroscopically curative resection and received adjuvant treatment was 15.3-18.2 months $(5,6,14)$. The patients enrolled in these studies had been treated before 2012, and it was assumed that most patients received gemcitabine as postoperative treatment. Adjuvant chemotherapy for pancreatic cancer is changing worldwide, from gemcitabine to a more effective regimen. The JASPAC-01 trial demonstrated that the HRs for mortality and relapse with $\mathrm{S}-1$ compared to gemcitabine were $0.57(95 \% \mathrm{CI}=0.44-0.72 ; p<0.0001$ for superiority) and $0.60 \quad(95 \% \mathrm{CI}=0.47-0.76 ; \quad p<0.0001)$, respectively (8). In the JASPAC-01 trial, patients with CY1 were excluded; therefore, the efficacy of S-1 in patients with CY1 who underwent macroscopically curative resection is unknown. In our study, S-1 therapy improved RFS compared to gemcitabine therapy; however, OS was comparable. This suggests that S-1 therapy is insufficient for treating resected pancreatic cancer with CY1. 


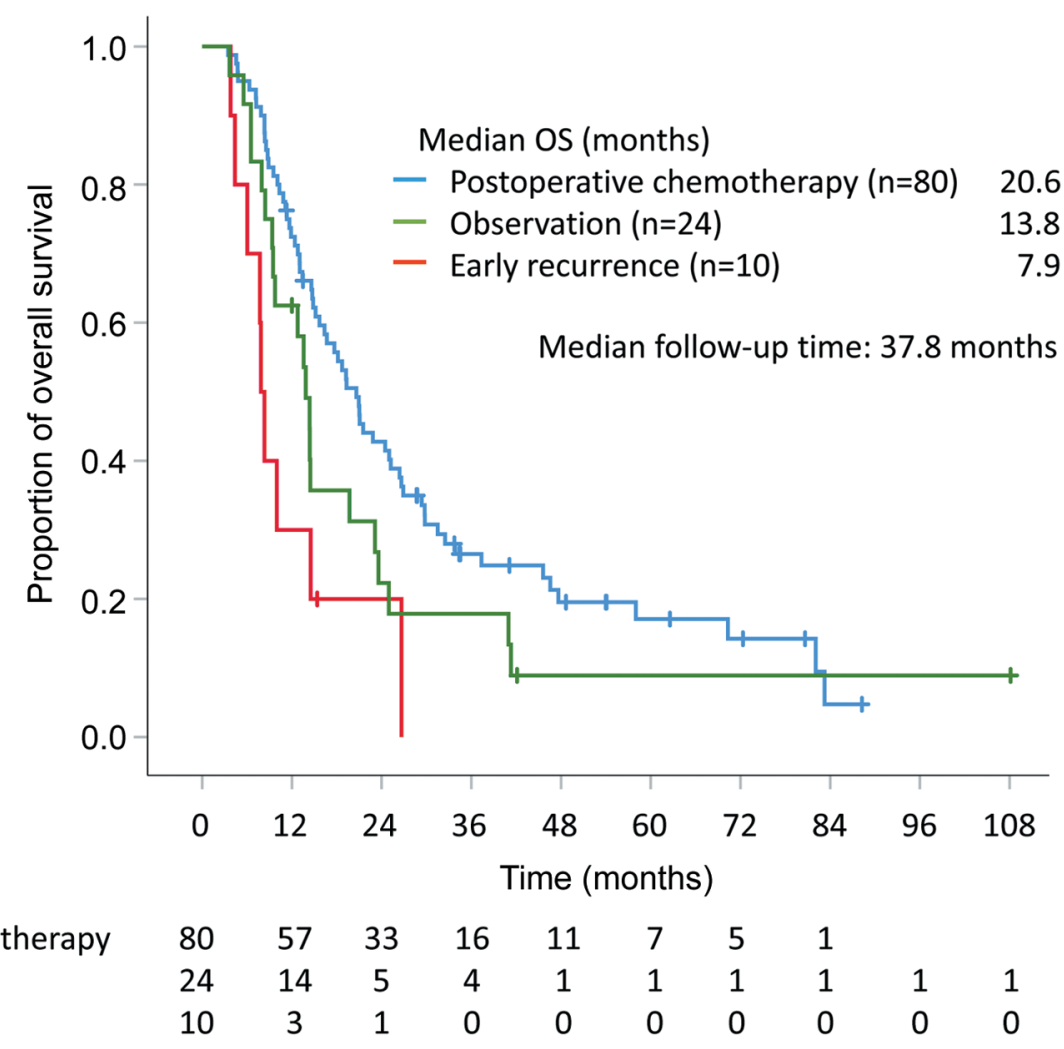

Figure 2. Kaplan-Meier curves of overall survival (OS) according to postoperative treatment of patients who underwent macroscopically curative resection. The blue, green, and red lines indicate postoperative treatment without recurrence, observation with no postoperative treatment, and early recurrence before starting postoperative treatment, respectively. The median OS of patients receiving postoperative treatment, undergoing observation, and with early recurrence was $20.6,13.8$, and 7.9 months, respectively.

A

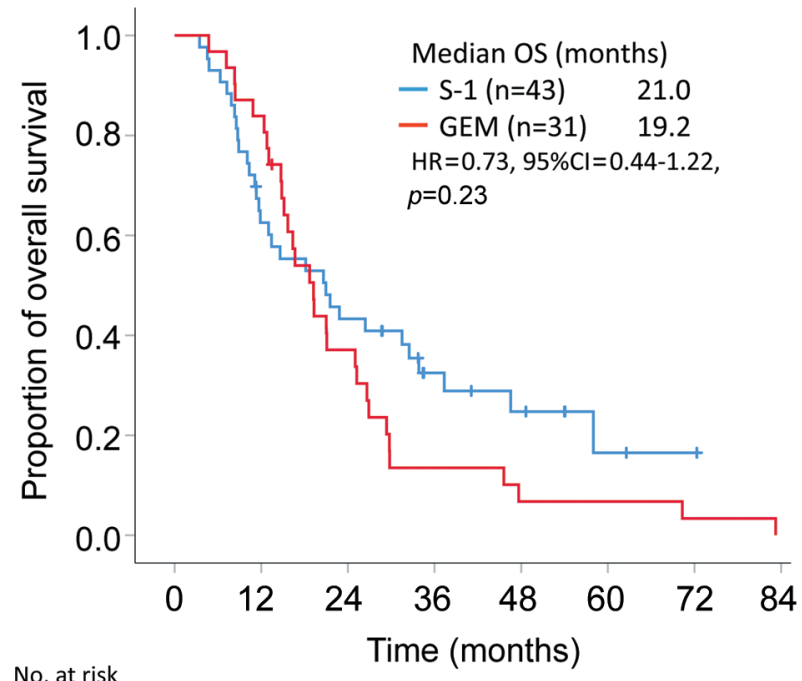

No. at risk

$\begin{array}{lllllllll}\text { S-1 } & 43 & 26 & 18 & 9 & 6 & 2 & 1 & \\ \text { GEM } & 31 & 26 & 11 & 4 & 2 & 2 & 1 & 1\end{array}$

B

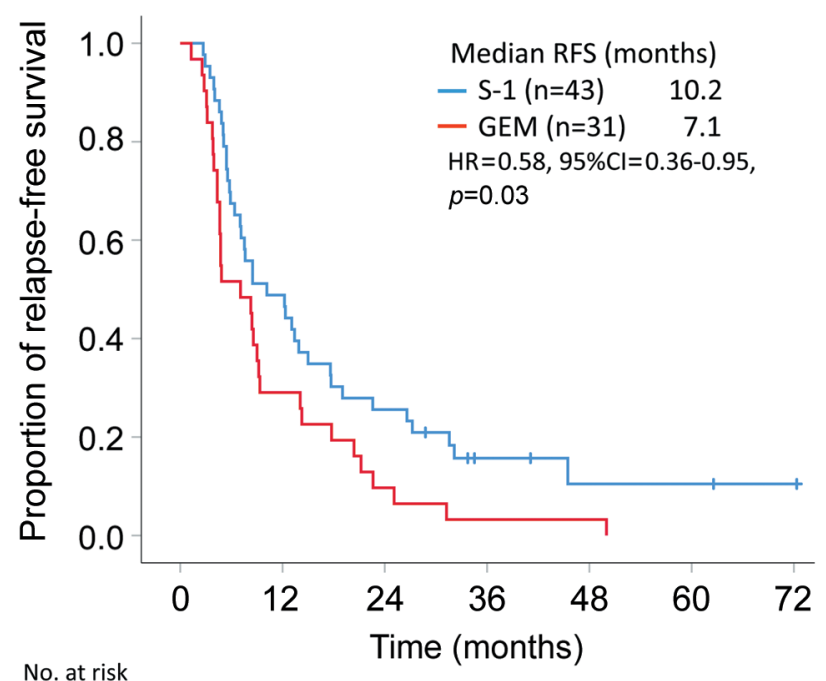

$\begin{array}{llllllll}\text { S-1 } & 43 & 21 & 11 & 4 & 2 & 2 & 1 \\ \text { GEM } & 31 & 13 & 3 & 1 & 1 & 0 & 0\end{array}$

Figure 3. Kaplan-Meier curves of (A) overall survival $(O S)$ and (B) relapse-free survival (RFS) according to the postoperative treatment regimen. The blue and red lines indicate $S-1$ and gemcitabine therapy, respectively. The median OS and RFS of patients treated with $S$ - 1 and gemcitabine therapy were 21.0 and 10.2 months and 19.2 and 7.1 months, respectively. 
Table III. Univariate and multivariate analyses of overall survival.

\begin{tabular}{|c|c|c|c|c|c|c|c|}
\hline \multirow[t]{2}{*}{ Factor } & \multirow[t]{2}{*}{$\mathrm{n}$} & \multicolumn{3}{|c|}{ Univariate } & \multicolumn{3}{|c|}{ Multivariate } \\
\hline & & HR & $95 \% \mathrm{CI}$ & $p$-Value & HR & $95 \% \mathrm{CI}$ & $p$-Value \\
\hline Age & 114 & 1.00 & $0.97-1.02$ & 0.84 & & & \\
\hline \multicolumn{8}{|l|}{ Gender } \\
\hline Male & 67 & & & & & & \\
\hline Female & 47 & 1.13 & $0.75-1.69$ & 0.57 & & & \\
\hline \multicolumn{8}{|l|}{ ECOG PS } \\
\hline 0 & 92 & & & & & & \\
\hline 1 & 19 & 0.93 & $0.54-1.59$ & 0.78 & & & \\
\hline \multicolumn{8}{|c|}{ Neoadjuvant therapy } \\
\hline No & 99 & & & & & & \\
\hline Yes & 15 & 0.90 & $0.48-1.70$ & 0.75 & & & \\
\hline \multicolumn{8}{|l|}{ EUS-FNA } \\
\hline No & 87 & & & & & & \\
\hline Yes & 27 & 0.96 & $0.59-1.57$ & 0.88 & & & \\
\hline CA19-9 & 111 & 1.00 & $1.00-1.00$ & 0.52 & & & \\
\hline NLR & 113 & 1.01 & $0.91-1.12$ & 0.88 & & & \\
\hline \multicolumn{8}{|l|}{ GPS score } \\
\hline 0 & 87 & & & & & & \\
\hline 1 & 16 & 1.22 & $0.69-2.17$ & 0.50 & & & \\
\hline 2 & 5 & 1.40 & $0.56-3.48$ & 0.47 & & & \\
\hline \multicolumn{8}{|l|}{ Type of surgery } \\
\hline $\mathrm{PD}$ & 44 & & & & & & \\
\hline DP & 55 & 0.71 & $0.46-1.10$ & 0.12 & 0.95 & $0.53-1.70$ & 0.86 \\
\hline DP-CAR & 7 & 1.56 & $0.69-3.49$ & 0.28 & 2.54 & $0.94-6.88$ & 0.07 \\
\hline $\mathrm{TP}$ & 8 & 2.4 & $1.06-5.46$ & 0.04 & 4.11 & $1.59-10.6$ & 0.004 \\
\hline \multicolumn{8}{|c|}{ Concomitant vascular resection } \\
\hline No & 80 & & & & & & \\
\hline Yes & 34 & 1.70 & $1.10-2.62$ & 0.02 & 1.02 & $0.55-1.90$ & 0.94 \\
\hline \multicolumn{8}{|l|}{ T stage (AJCC $\left.8^{\text {th }}\right)$} \\
\hline $\mathrm{T} 1$ & 8 & & & & & & \\
\hline $\mathrm{T} 2$ & 62 & 2.35 & $0.93-5.93$ & 0.07 & 1.96 & $0.76-5.07$ & 0.16 \\
\hline $\mathrm{T} 3$ & 44 & 2.64 & $1.03-6.72$ & 0.04 & 1.53 & $0.56-4.18$ & 0.40 \\
\hline \multicolumn{8}{|l|}{$\mathrm{N}$ stage (AJCC $\left.8^{\text {th }}\right)$} \\
\hline No & 26 & & & & & & \\
\hline N1 & 43 & 1.27 & $0.72-2.25$ & 0.41 & 1.36 & $0.71-2.59$ & 0.36 \\
\hline $\mathrm{N} 2$ & 45 & 2.09 & $1.20-3.65$ & 0.01 & 1.94 & $0.97-3.85$ & 0.06 \\
\hline \multicolumn{8}{|c|}{ Resection margin status } \\
\hline R0 & 76 & & & & & & \\
\hline $\mathrm{R} 1$ & 31 & 1.89 & $1.19-2.98$ & 0.007 & 1.93 & $1.11-3.37$ & 0.02 \\
\hline \multicolumn{8}{|c|}{ Tumour differentiation } \\
\hline Well & 27 & & & & & & \\
\hline Moderate & 74 & 1.42 & $0.86-2.34$ & 0.17 & & & \\
\hline Poor & 13 & 1.80 & $0.89-3.67$ & 0.11 & & & \\
\hline \multicolumn{8}{|c|}{ Postoperative chemotherapy } \\
\hline Gemcitabine & 31 & & & & & & \\
\hline S-1 & 43 & 0.74 & $0.44-1.22$ & 0.24 & & & \\
\hline Other regimens & 6 & 0.39 & $0.13-1.11$ & 0.08 & & & \\
\hline No treatment & 34 & 1.41 & $0.85-2.34$ & 0.19 & & & \\
\hline
\end{tabular}

The PRODIGE 24/CCTG PA.6 is a phase III, multicentre, randomized clinical trial of postoperative leucovorin calcium, fluorouracil, irinotecan hydrochloride, and oxaliplatin (mFOLFIRINOX) versus gemcitabine alone for curatively resected pancreatic cancer (15). The median disease-free survival was $12.8(95 \% \mathrm{CI}=11.7-15.2)$ months for patients in the gemcitabine arm and $21.6(95 \% \mathrm{CI}=17.5-26.7)$ months for those in the mFOLFIRINOX arm $(\mathrm{HR}=0.58,95 \% \mathrm{CI}=0.46-$ 0.73). The median OS was $35.0(95 \% \mathrm{CI}=28.7-43.9)$ and 54.4 (95\% CI=41.8-not reached) months, respectively, favouring the 
Table IV. Univariate and multivariate analyses of and relapse-free survival.

\begin{tabular}{|c|c|c|c|c|c|c|c|}
\hline \multirow[t]{2}{*}{ Factor } & \multirow[t]{2}{*}{$\mathrm{n}$} & \multicolumn{3}{|c|}{ Univariate } & \multicolumn{3}{|c|}{ Multivariate } \\
\hline & & HR & $95 \% \mathrm{CI}$ & $p$-Value & HR & $95 \% \mathrm{CI}$ & $p$-Value \\
\hline Age & 114 & 1.00 & $0.97-1.02$ & 0.66 & & & \\
\hline \multicolumn{8}{|l|}{ Gender } \\
\hline Male & 67 & & & & & & \\
\hline Female & 47 & 0.99 & $0.67-1.45$ & 0.95 & & & \\
\hline \multicolumn{8}{|l|}{ ECOG PS } \\
\hline 0 & 92 & & & & & & \\
\hline 1 & 19 & 0.70 & $0.41-1.19$ & 0.19 & & & \\
\hline \multicolumn{8}{|c|}{ Neoadjuvant therapy } \\
\hline No & 99 & & & & & & \\
\hline Yes & 15 & 0.77 & $0.43-1.38$ & 0.38 & & & \\
\hline \multicolumn{8}{|l|}{ EUS-FNA } \\
\hline No & 87 & & & & & & \\
\hline Yes & 27 & 0.98 & $0.62-1.54$ & 0.92 & & & \\
\hline CA19-9 & 111 & 1.00 & $1.00-1.00$ & 0.69 & & & \\
\hline NLR & 113 & 1.01 & $0.92-1.12$ & 0.78 & & & \\
\hline \multicolumn{8}{|l|}{ GPS score } \\
\hline 0 & 87 & & & & & & \\
\hline 1 & 16 & 1.18 & $0.69-2.02$ & 0.55 & & & \\
\hline 2 & 5 & 1.46 & $0.59-3.63$ & 0.41 & & & \\
\hline \multicolumn{8}{|l|}{ Type of surgery } \\
\hline PD & 44 & & & & & & \\
\hline DP & 55 & 0.78 & $0.51-1.19$ & 0.25 & 0.92 & $0.51-1.66$ & 0.78 \\
\hline DP-CAR & 7 & 2.16 & $0.96-4.86$ & 0.06 & 2.42 & $0.93-6.29$ & 0.07 \\
\hline $\mathrm{TP}$ & 8 & 2.36 & $1.10-5.09$ & 0.03 & 1.73 & $0.75-3.99$ & 0.20 \\
\hline \multicolumn{8}{|c|}{ Concomitant vascular resection } \\
\hline No & 80 & & & & & & \\
\hline Yes & 34 & 1.82 & $1.20-2.75$ & 0.005 & 1.70 & $0.93-3.10$ & 0.09 \\
\hline \multicolumn{8}{|l|}{ T stage (AJCC $\left.8^{\text {th }}\right)$} \\
\hline $\mathrm{T} 1$ & 8 & & & & & & \\
\hline $\mathrm{T} 2$ & 62 & 3.32 & $1.29-8.51$ & 0.013 & 2.79 & $1.04-7.50$ & 0.04 \\
\hline $\mathrm{T} 3$ & 44 & 4.20 & $1.62-10.89$ & 0.003 & 3.01 & $1.06-8.50$ & 0.04 \\
\hline \multicolumn{8}{|l|}{$\mathrm{N}$ stage (AJCC $\left.8^{\text {th }}\right)$} \\
\hline No & 26 & & & & & & \\
\hline N1 & 43 & 1.17 & $0.70-1.97$ & 0.55 & 1.10 & $0.60-2.03$ & 0.75 \\
\hline $\mathrm{N} 2$ & 45 & 1.76 & $1.05-2.95$ & 0.03 & 1.49 & $0.77-2.89$ & 0.23 \\
\hline \multicolumn{8}{|c|}{ Resection margin status } \\
\hline R0 & 76 & & & & & & \\
\hline $\mathrm{R} 1$ & 31 & 1.54 & $1.00-2.38$ & 0.05 & & & \\
\hline \multicolumn{8}{|c|}{ Tumour differentiation } \\
\hline Well & 27 & & & & & & \\
\hline Moderate & 74 & 1.16 & $0.73-1.83$ & 0.54 & 1.64 & $0.96-2.81$ & 0.07 \\
\hline Poor & 13 & 2.46 & $1.25-4.84$ & 0.009 & 4.02 & $1.88-8.60$ & $<0.001$ \\
\hline \multicolumn{8}{|c|}{ Postoperative chemotherapy } \\
\hline Gemcitabine & 31 & & & & & & \\
\hline S-1 & 43 & 0.60 & $0.37-0.97$ & 0.04 & 0.59 & $0.35-0.99$ & 0.05 \\
\hline Other regimens & 6 & 0.57 & $0.24-1.38$ & 0.22 & 0.41 & $0.15-1.01$ & 0.07 \\
\hline No treatment & 34 & 1.30 & $0.79-2.14$ & 0.30 & 1.31 & $0.74-2.29$ & 0.36 \\
\hline
\end{tabular}

ECOG PS: Eastern Cooperative Oncology Group performance status; EUS-FNA: endoscopic ultrasound-fine needle aspiration; CA19-9: carbohydrate antigen 19-9; NLR: neutrophil-to-lymphocyte ratio; GPS: Glasgow Prognostic Score; AJCC 8th: American Joint Committee on Cancer staging system (eighth edition); PD: pancreatoduodenectomy; DP: distal pancreatectomy; DP-CAR: distal pancreatectomy with celiac axis resection; TP: total pancreatectomy.

mFOLFIRINOX arm $(\mathrm{HR}=0.64,95 \% \mathrm{CI}=0.48-0.86)$. Based on these results, in the National Comprehensive Cancer Network and American Society of Clinical Oncology clinical practice guidelines, mFOLFIRINOX is the preferred regimen for the adjuvant treatment of patients with an ECOG PS of 0 or 1, following resection $(3,16)$. FOLFIRINOX is unapproved as 
Table V. Patient characteristics according to the regimen.

\begin{tabular}{|c|c|c|c|c|}
\hline \multicolumn{2}{|l|}{ Characteristic } & \multirow{2}{*}{$\frac{S-1(n=43)}{66}$} & \multirow{2}{*}{$\frac{\text { Gemcitabine }(\mathrm{n}=31)}{66}$} & \multirow{2}{*}{$\frac{p \text {-Value }}{0.66}$} \\
\hline Age (years) & Median & & & \\
\hline Gender & Male/Female & $22 / 21$ & $18 / 13$ & 0.56 \\
\hline ECOG PS & 0/1/Unknown & $36 / 7 / 0$ & $23 / 6 / 2$ & 0.22 \\
\hline Neoadjuvant therapy & Yes/No & $9 / 34$ & $4 / 27$ & 0.37 \\
\hline EUS-FNA & Yes/No & $13 / 30$ & $6 / 25$ & 0.29 \\
\hline CA19-9 level (U/ml) & Median & 178.5 & 287 & 0.21 \\
\hline NLR & Median (range) & $2.31(0.89-4.08)$ & $2.54(1.33-6.31)$ & 0.39 \\
\hline GPS & 0/1/2/Unknown & $33 / 7 / 1 / 2$ & $24 / 5 / 0 / 2$ & 0.70 \\
\hline Type of surgery & $\mathrm{PD} / \mathrm{DP} / \mathrm{DP}-\mathrm{CAR} / \mathrm{TP}$ & $17 / 23 / 1 / 2$ & $11 / 16 / 3 / 1$ & 0.58 \\
\hline Concomitant vascular resection & Yes/No & $10 / 33$ & $8 / 23$ & 0.80 \\
\hline Postoperative complications ( $\geq \mathrm{CD}$ III) & Yes/No & $11 / 32$ & $10 / 21$ & 0.53 \\
\hline Tumour differentiation & Well/Mod/Poor & $5 / 35 / 3$ & $9 / 18 / 4$ & 0.09 \\
\hline T stage (AJCC 8th) & $1 / 2 / 3$ & $4 / 25 / 14$ & $3 / 12 / 16$ & 0.23 \\
\hline $\mathrm{N}$ stage (AJCC 8th) & $0 / 1 / 2$ & $9 / 16 / 18$ & $9 / 13 / 9$ & 0.50 \\
\hline Resection margin status & R0/R1/Unknown & $28 / 13 / 2$ & $22 / 7 / 2$ & 0.75 \\
\hline
\end{tabular}

ECOG PS: Eastern Cooperative Oncology Group performance status; EUS-FNA: endoscopic ultrasound-fine needle aspiration; CA19-9: carbohydrate antigen 19-9; NLR: neutrophil-to-lymphocyte ratio; GPS: Glasgow Prognostic Score; CD: Clavien-Dindo classification; AJCC 8th:American Joint Committee on Cancer staging system (eighth edition); PD: pancreatoduodenectomy; DP: distal pancreatectomy; DP-CAR: distal pancreatectomy with celiac axis resection.; TP: total pancreatectomy.

adjuvant chemotherapy in Japan, and its tolerability and feasibility as postoperative treatment for patients undergoing resection are unknown. Therefore, even if CY1 is regarded as M1 disease, it is unlikely that FOLFIRINOX is administered to patients with CY1 who underwent macroscopically curative resection in Japan.

Several studies have reported that CY1 is associated with poor prognosis in patients who underwent curative resection (5, 6, 14, 17-22). In addition to CY1, the following prognostic factors were identified: preoperative serum CA199 levels, tumour location, tumour size, portal vein resection, lymph node metastasis, residual tumour, tumour differentiation, vascular invasion, lymphatic invasion, bile duct invasion, and adjuvant chemotherapy (5, 6, 14, 19, 20, 22-24). In contrast, some studies have reported that no prognostic factors were identified, or that CY1 was an insignificant prognostic factor $(14,21)$. In our study, total pancreatectomy and R1 resection were associated with poor prognosis. As shown in these studies, many prognostic factors have been reported in pancreatic cancer, and it is unlikely that specific factors define prognosis.

Preoperative treatment is becoming the standard therapy for resectable pancreatic cancer. In the Prep-02/JSAP-05 trial, the combination chemotherapy of gemcitabine and S1 , as neoadjuvant treatment for resectable pancreatic cancer, significantly improved survival (25). It has also been reported that $7 \%(4 / 56)$ of patients who received neoadjuvant chemotherapy had positive peritoneal lavage cytology (26). However, both neoadjuvant therapy and postoperative treatment with S-1 were not significantly associated with
Table VI. Recurrence sites according to postoperative chemotherapy.

\begin{tabular}{lcc}
\hline & $\begin{array}{c}\mathrm{S}-1, \mathrm{n}=43 \\
\mathrm{~N}(\%)\end{array}$ & $\begin{array}{c}\text { Gemcitabine, } \mathrm{n}=31 \\
\mathrm{~N}(\%)\end{array}$ \\
\hline Recurrence & $37(86)$ & $31(100)$ \\
Peritoneum & $19(44)$ & $12(39)$ \\
Liver & $15(35)$ & $8(26)$ \\
Local recurrence & $6(14)$ & $8(26)$ \\
Lymph nodes & $5(12)$ & $5(16)$ \\
Lung & $2(4.7)$ & $5(16)$ \\
\hline
\end{tabular}

survival in our analysis. This suggests that CY1 may be a strong poor prognostic factor. Although resection for pancreatic cancer with CY1 has been controversial, comprehensive treatment strategies including perioperative chemotherapy, duration of treatment, and surgical treatment should be considered. The development of perioperative treatments will continue to improve the survival of patients with pancreatic cancer. It is expected that more effective treatments will be established to overcome various poor prognostic factors, including CY1.

This study has some limitations. First, a central review of peritoneal lavage cytology was not performed. Therefore, to accumulate reliable subjects, Papanicolaou Class IV and V were included, while Class III was excluded. Second, the duration of postoperative treatment was not uniform. However, patients in whom postoperative treatment was started within 3 months were included in the postoperative treatment group. 
Furthermore, in terms of postoperative treatment, this study included the largest number of patients with CY1, and we believe that the results shown will be useful.

In conclusion, most patients with pancreatic cancer with CY1 who underwent macroscopically curative resection received S-1 therapy as postoperative treatment following the report of the JASPAC-01 trial, and the median OS and RFS were 21.0 and 10.2 months, respectively. However, its efficacy is insufficient, and further studies on the postoperative treatment of patients with resectable pancreatic cancer with CY1 are required.

\section{Conflicts of Interest}

The Authors have no competing interests to disclose in relation to this study.

\section{Authors' Contributions}

Study concepts: AT and JF; study design: AT; data acquisition: AT, SN, FM, SM, RT, RH, MK, HS, HT, HO, HN, KS, KS and AA; data analysis and manuscript preparation: AT; statistical analysis, interpretation and manuscript editing: all Authors; and manuscript review and approval: all Authors.

\section{Acknowledgements}

The Authors would like to thank the patients and their families for participating in this study. The Authors would also like to thank Editage (www.editage.com) for their writing support. This study was supported by the Shizuoka Cancer Center Medical Fund (Shizuoka, Japan).

\section{References}

1 Siegel RL, Miller KD and Jemal A: Cancer statistics, 2020. CA Cancer J Clin 70(1): 7-30, 2020. PMID: 31912902. DOI: $10.3322 /$ caac. 21590

2 Cancer Registry and Statistics. Cancer Information Service, National Cancer Center, Japan. Available at: https:// ganjoho.jp/reg_stat/statistics/stat/summary.html. [Last accessed on June 20, 2021]

3 National Comprehensive Cancer Network. NCCN Guidelines Version 22021 Pancreatic Adenocarcinoma. Available at: https://www.nccn.org/professionals/physician_gls/pdf/pancreatic. pdf [Last accessed on June 20, 2021]

4 Amin MB, Edge S, Greene F, Byrd DR, Brookland RK, Washington MK, Gershenwald JE, Compton CC, Hess KR, Sullivan DC, Jessup JM, Brierley JD, Gaspar LE, Schilsky RL, Balch CM, Winchester DP, Asare EA, Madera M, Gress DM and Meyeret LR: AJCC Cancer Staging Manual. $8^{\text {th }}$ ed. New York, Springer, pp. 337347, 2017.

5 Satoi S, Murakami Y, Motoi F, Uemura K, Kawai M, Kurata M, Sho M, Matsumoto I, Yanagimoto H, Yamamoto T, Mizuma M, Unno M, Hashimoto Y, Hirono S, Yamaue H, Honda G, Nagai M, Nakajima Y, Shinzeki M, Fukumoto $\mathrm{T}$ and Kwon AH: Reappraisal of peritoneal washing cytology in 984 patients with pancreatic ductal adenocarcinoma who underwent marginnegative resection. J Gastrointest Surg 19(1): 6-14; discussion 14, 2015. PMID: 25316482. DOI: 10.1007/s11605-014-2637-7

6 Tsuchida H, Fujii T, Mizuma M, Satoi S, Igarashi H, Eguchi H, Kuroki T, Shimizu Y, Tani M, Tanno S, Tsuji Y, Hirooka Y, Masamune A, Mizumoto K, Itoi T, Egawa S, Kodama Y, Hamada S, Unno M, Yamaue H, Okazaki K and Committee of Clinical Research, Japan Pancreas Society: Prognostic importance of peritoneal washing cytology in patients with otherwise resectable pancreatic ductal adenocarcinoma who underwent pancreatectomy: A nationwide, cancer registry-based study from the Japan Pancreas Society. Surgery 166(6): 9971003, 2019. PMID: 31445763. DOI: 10.1016/j.surg.2019.06.023

7 Oettle H, Neuhaus P, Hochhaus A, Hartmann JT, Gellert K, Ridwelski K, Niedergethmann M, Zülke C, Fahlke J, Arning MB, Sinn M, Hinke A and Riess H: Adjuvant chemotherapy with gemcitabine and long-term outcomes among patients with resected pancreatic cancer: the CONKO-001 randomized trial. JAMA 310(14): 1473-1481, 2013. PMID: 24104372. DOI: 10.1001/jama.2013.279201

8 Uesaka K, Boku N, Fukutomi A, Okamura Y, Konishi M, Matsumoto I, Kaneoka Y, Shimizu Y, Nakamori S, Sakamoto H, Morinaga S, Kainuma O, Imai K, Sata N, Hishinuma S, Ojima H, Yamaguchi R, Hirano S, Sudo T, Ohashi Y and JASPAC 01 Study Group: Adjuvant chemotherapy of S-1 versus gemcitabine for resected pancreatic cancer: a phase 3, open-label, randomised, non-inferiority trial (JASPAC 01). Lancet 388(10041): 248-257, 2016. PMID: 27265347. DOI: 10.1016/ S0140-6736(16)30583-9

9 Japan Pancreas Society: General Rules for the Study of Pancreatic Cancer. 7th ed. Tokyo, Japan, Kanehara \& Co., 2016.

10 Dindo D, Demartines N and Clavien PA: Classification of surgical complications: a new proposal with evaluation in a cohort of 6336 patients and results of a survey. Ann Surg 240(2): 205-213, 2004. PMID: 15273542. DOI: 10.1097/01.sla.000 0133083.54934.ae

11 Clavien PA, Barkun J, de Oliveira ML, Vauthey JN, Dindo D, Schulick RD, de Santibañes E, Pekolj J, Slankamenac K, Bassi C, Graf R, Vonlanthen R, Padbury R, Cameron JL and Makuuchi M: The Clavien-Dindo classification of surgical complications: five-year experience. Ann Surg 250(2): 187-196, 2009. PMID: 19638912. DOI: $10.1097 /$ SLA.0b013e3181b13ca2

12 Forrest LM, McMillan DC, McArdle CS, Angerson WJ and Dunlop DJ: Evaluation of cumulative prognostic scores based on the systemic inflammatory response in patients with inoperable non-small-cell lung cancer. Br J Cancer 89(6): 10281030, 2003. PMID: 12966420. DOI: 10.1038/sj.bjc.6601242

13 Forrest LM, McMillan DC, McArdle CS, Angerson WJ and Dunlop DJ: Comparison of an inflammation-based prognostic score (GPS) with performance status (ECOG) in patients receiving platinum-based chemotherapy for inoperable nonsmall-cell lung cancer. Br J Cancer 90(9): 1704-1706, 2004. PMID: 15150622 . DOI: 10.1038/sj.bjc.6601789

14 Yamada S, Fujii T, Kanda M, Sugimoto H, Nomoto S, Takeda S, Nakao A and Kodera Y: Value of peritoneal cytology in potentially resectable pancreatic cancer. Br J Surg 100(13): 1791-1796, 2013. PMID: 24227366. DOI: 10.1002/bjs.9307

15 Conroy T, Hammel P, Hebbar M, Ben Abdelghani M, Wei AC, Raoul JL, Choné L, Francois E, Artru P, Biagi JJ, Lecomte T, Assenat E, Faroux R, Ychou M, Volet J, Sauvanet A, Breysacher 
G, Di Fiore F, Cripps C, Kavan P, Texereau P, Bouhier-Leporrier K, Khemissa-Akouz F, Legoux JL, Juzyna B, Gourgou S, O'Callaghan CJ, Jouffroy-Zeller C, Rat P, Malka D, Castan F, Bachet JB and Canadian Cancer Trials Group and the UnicancerGI-PRODIGE Group: FOLFIRINOX or gemcitabine as adjuvant therapy for pancreatic cancer. N Engl J Med 379(25): 23952406, 2018. PMID: 30575490. DOI: 10.1056/NEJMoa1809775

16 Khorana AA, McKernin SE, Berlin J, Hong TS, Maitra A, Moravek C, Mumber M, Schulick R, Zeh HJ and Katz MHG: Potentially curable pancreatic adenocarcinoma: ASCO clinical practice guideline update. J Clin Oncol 37(23): 2082-2088, 2019. PMID: 31180816 . DOI: $10.1200 / J C O .19 .00946$

17 Yin Z, Ma T and Chen S: Intraoperative peritoneal washing cytology on survival in pancreatic ductal adenocarcinoma with resectable, locally advanced, and metastatic disease. Pancreas 48(4): 519-525, 2019. PMID: 30946232. DOI: 10.1097/MPA.00 00000000001266

18 Cao F, Li J, Li A and Li F: Prognostic significance of positive peritoneal cytology in resectable pancreatic cancer: a systemic review and meta-analysis. Oncotarget 8(9): 15004-15013, 2017. PMID: 28122342. DOI: 10.18632/oncotarget.14745

19 Hoshimoto S, Hishinuma S, Shirakawa H, Tomikawa M, Ozawa I, Hoshi N, Hoshi S, Hirabayashi K and Ogata Y: Prognostic significance of intraoperative peritoneal washing cytology for patients with potentially resectable pancreatic ductal adenocarcinoma. Pancreatology 17(1): 109-114, 2017. PMID: 27840175. DOI: 10.1016/j.pan.2016.11.001

20 Abe T, Ohuchida K, Endo S, Ookubo F, Mori Y, Nakata K, Miyasaka Y, Manabe T, Ohtsuka T, Nagai E, Oda Y and Nakamura M: Clinical importance of intraoperative peritoneal cytology in patients with pancreatic cancer. Surgery 161(4): 951958, 2017. PMID: 27939334. DOI: 10.1016/j.surg.2016.10.035

21 Iwagami Y, Eguchi H, Wada H, Tomimaru Y, Hama N, Kawamoto K, Kobayashi S, Mori M, Doki Y and Nagano H: Implications of peritoneal lavage cytology in resectable leftsided pancreatic cancer. Surg Today 45(4): 444-450, 2015. PMID: 24975140. DOI: 10.1007/s00595-014-0964-7

22 Hirabayashi K, Imoto A, Yamada M, Hadano A, Kato N, Miyajima Y, Ito H, Kawaguchi Y, Nakagohri T, Mine T and Nakamura N: Positive intraoperative peritoneal lavage cytology is a negative prognostic factor in pancreatic ductal adenocarcinoma: a retrospective single-center study. Front Oncol 5: 182, 2015. PMID: 26301205. DOI: 10.3389/fonc.2015.00182
23 Takahashi H, Akita H, Wada H, Tomokuni A, Asukai K, Takahashi Y, Yanagimoto Y, Matsunaga T, Sugimura K, Yamamoto K, Nishimura J, Yasui M, Omori T, Miyata H, Yamamoto T, Nakanishi M, Shirayanagi M, Yamasaki T, Ohue M, Yano M, Sakon M and Ishikawa O: Subclinical cancer cell dissemination in peritoneal lavage fluid detected by reversetranscription polymerase chain reaction identifies patients at high risk for peritoneal recurrence and consequent impaired survival in the setting of preoperative chemoradiation therapy for pancreatic cancer. Surgery 164(6): 1168-1177, 2018. PMID: 30146098. DOI: $10.1016 /$ j.surg.2018.06.047

24 Aoyama T, Katayama Y, Murakawa M, Shiozawa M, Morimoto M, Yamamoto N, Yoshikawa T, Rino Y, Masuda M and Morinaga S: Clinical implication of peritoneal cytology in the pancreatic cancer patients who underwent curative resection followed by adjuvant gemcitabine or S-1 chemotherapy. Hepatogastroenterology 62(137): 200-206, 2015. PMID: 25911897.

25 Unno M, Motoi F, Matsuyama Y, Satoi S, Matsumoto I, Aosasa S, Shirakawa H, Wada K, Fujii T, Yoshitomi H, Takahashi S, Sho M, Ueno H and Kosuge T: Randomized phase II/III trial of neoadjuvant chemotherapy with gemcitabine and S-1 versus upfront surgery for resectable pancreatic cancer (Prep-02/JSAP05). Journal of Clinical Oncology 37(4_suppl): 189-189, 2020. DOI: 10.1200/JCO.2019.37.4_suppl.189

26 Mori S, Aoki T, Sakuraoka Y, Shimizu T, Yamaguchi T, Park $\mathrm{KH}$, Matsumoto T, Shiraki T, Iso Y and Kubota K: Efficacy of adjuvant chemotherapy according to the pathological response to neoadjuvant chemotherapy among patients with pancreatic ductal adenocarcinoma. Anticancer Res 41(3): 1629-1639, 2021. PMID: 33788759. DOI: 10.21873/anticanres.14925 